\title{
Evaluation of Topramezone on Zebrafish Retinoid Signaling
}

\author{
Haixing Liu ${ }^{1}$, Pengxing $\mathrm{Xu}^{1}$, Yu Fan ${ }^{1}$, Weizhi Zhang ${ }^{1,}$ \\ ${ }^{1}$ Department of Biochemistry and Molecular Biology, Hubei University of \\ Technology, Wuhan 430065, China
}

Running title: Topramezone on retinoid signaling

Keywords: Topramezone; Retinoid signaling; Zebrafish 


\section{ABSTRACT}

Topramezone is a highly selective herbicide developed for broadleaf and grass weeds control in corn. In this study, the effects of topramezone on zebrafish, especially in retinoid signaling were investigated. Zebrafish embryos were treated with topramezone from 4 hours post-fertilization (hpf) to $144 \mathrm{hpf}$. Exposed to topramezone significantly reduced the retinal and retinoic levels compared to controls. The transcriptional expression levels of retinol dehydrogenase (rdh1), retinoic acid receptor subunit (raraa), retinal dehydrogenase (raldh2), retinol binding protein (rbp1a), and cellular retinoic acid binding protein (crabp1a and crabp2a) were significantly decreased. Our results suggested that topramezone significantly impaired zebrafish retinoid signaling during a short time exposure. However, treatment with topramezone significantly increased the mRNA expression levels of zfblue, zfrho, zfgr1, zfuv, and zfred. Our data demonstrated that topramezone treatment could interrupt retinoid signaling and further affect zebrafish eye development. 


\section{INTRODUCTION}

Topramezone [3-(4,5-dihydro-1,2-oxazol-3-yl)-4-mesyl-o-tolyl] (5-hydroxy1-methylpyrazol-4-yl) methanone, which has been commercially introduced in 2006 [1-3], is a highly selective herbicide and widely used for broadleaf weeds and annual grass control in corn and wheat [3-7]. The aquatic environments have been polluted by herbicide due to surface runoff, direct overspray or drift while applying the herbicide [8-12].

Topramezone is a 4-HPPD inhibitor, which leads to increased serum tyrosine levels [1, 13-15]. Previous studies have reported that topramezone causes a dose-dependent elevated adverse effects on the thyroid levels in rats $[16,17]$. Thus, topramezone has the potential risk to the wildlife and human health. Although topramezone has been widely used for 10 more years, few studies have investigated the effects of topramezone exposure to the aquatic organisms. Topramezone residues enter the aquatic ecosystems mainly due to the drift or runoff [18]. Thus, with the wide usage of the topramezone-based herbicides, it has raised to be a primary problem to evaluate the safety and environmental impacts of this pesticide in the environmental toxicology.

Retinoic acid (RA) acts in pattern formation and organogenesis during the vertebrate development [19-21]. The synthesis of RA from retinol need two sequential steps, first is the oxidation of retinol to retinal and then retinal is oxidized to RA [20, 22, 23]. Upon synthesis, RA can bind to the nuclear ligandactivated transcription factors, such as RA receptors- $\alpha, \beta$ and $\gamma$ which can 
dimerize with RXRs- $\alpha, \beta$ and $\gamma$ to regulate the target genes expression [24-26].

Abnormal RA signaling in vertebrate embryos impacts various organ

developments, such as the branchial arches and the nervous system [27-30].

In this study, we aimed to access the effects of topramezone treatment on retinoid signaling and the zebrafish eye development. Zebrafish embryos were exposed to different concentrations of topramezone, the mRNA expression levels of the key genes involved in retinoid signaling pathway was examined.

\section{MATERIALS AND METHODS}

\section{Chemicals}

Topramezone, DMSO, standards for retinol, retinal and retinoic acid were purchased from Sigma Aldrich (St Louis, MO, USA). Chemicals used for retinoid measurement were of HPLC grade.

\section{Zebrafish maintenance and topramezone treatment}

Wild-type zebrafish were maintained and raised as described previously [31, 32]. Developmental stages of zebrafish embryos were characterized as described previously [33].

Sixty zebrafish eggs were incubated in the topramezone exposure solutionn $(0,1,10$ and $100 \mathrm{mg} / \mathrm{L})$ from $4 \mathrm{hpf}$ to $144 \mathrm{hpf}$. Control group treated with $0.01 \%(\mathrm{v} / \mathrm{v})$ DMSO. Water was changed twice daily. The embryos were 
collected, immediately frozen in liquid nitrogen and stored at $-80^{\circ} \mathrm{C}$ for subsequent gene, protein and retinoid analysis at $144 \mathrm{hpf}$.

\section{RT-PCR}

Twenty embryos from each treated group was collected and total RNA was extracted using TRIzol (Invitrogen) according to the manufacturer's instruction, and single-stranded cDNA was systhesized as described previously $[34,35]$.

\section{Real-time qPCR}

Real-time quantitative PCR (qPCR) was carried out as previous described $[36,37]$. Relative gene transcription levels were determined after normalizing to the mRNA content of reference gene $\beta$-actin. The primers used in this study was described somewhere else.

\section{Retinoid measurement}

The extraction and measurement of retinoid profiles was carried out as previously described [38].

\section{Statistical analyses}

All data are presented as the mean \pm SE and the statistical significance was set at $p \leq 0.05$. All statistical analyses were performend using SPSS 18 software. Differences between two groups were evaluated by the one-way ANOVA test followed by Tukey's test. 


\section{RESULTS}

\section{Exposed to topramezone caused developmental toxicity in zebrafish}

Embryos were treated with $0,1,10$ and $100 \mu \mathrm{g} / \mathrm{L}$ of topramezone from 4 hpf to $144 \mathrm{hpf}$, the survival rates of each treated group was $93 \pm 2.2 \%, 86 \pm 3.1$ $\%, 75 \pm 6.3 \%$ and $20 \pm 2.4 \%$, respectively. These data showed a significant lower survival rates after $100 \mu \mathrm{g} / \mathrm{L}$ topramezone exposure. The larvae appeared developmental toxicity after $48 \mathrm{hpf}$, and the hatching rates were also significant decreased after $72 \mathrm{hpf}$ in the higher topramezone treatment.

\section{Topramezone exposure affected the retinoid profiles}

After treated with different concentration of topramezone, zebrafish larvae were collected and analyzed. Retinal contents were significantly decreased in the $10 \mu \mathrm{g} / \mathrm{L}$ topramezone treated embryos and RA levels were significantly lower in the topramezone-treated groups compared to the untreated controls (Table 1). The RA contents were reduced in a dose-dependent manner (Table 1).

\section{Topramezone treatment changed the mRNA expression levels}

The transcriptional expression of key genes involved in intracellular retinol and retinal transport, such as crbp1a, were significant diminished (Fig. 1). The mRNA expression level of retinol dehydrogenase ( $r d h 1)$, which converts retinol 
into retinal, was significantly decreased; however, the transcriptional expression of raldh2, which transforms retinal to RA, was significantly increased (Fig. 1). The transcriptional expression levels of crabp1a and crabp2a, which are the two isoforms of the cellular retinoic acid binding proteins, were significantly decreased in the embryos exposed to topramezone (Fig. 1). We also observed that the mRNA expression level of raraa was downregulated in a dosedependent manner in the embryos treated with topramezone (Fig. 1). The mRNA expression levels of five key genes that encode the rhodopsin and ultraviolet, red, blue and green opsins, as zfrho, zfuv, zfred, zfblue and zfgr1, were increased in a dose-dependent manner in the topramezone exposed embryos (Fig. 2).

\section{DISCUSSION}

The disruptive effects of topramezone treatment on retinoid contents and its effects on fish eye development are largely undefined. In the present study, we treated zebrafish embryos with topramezone to explore its role on the eye developmental process and related signaling pathway. Our results suggested that topramezone exposure could interrupt retinoid signaling and further affect the zebrafish eye development.

The total retinol levels had no significantly changes in the topramezone treated zebrafish larvae. Different responses to various concentrations of toxins might be explained by different exposed duration. Thus, treated with 
topramezone had no overt effect on the retinol contents in the zebrafish embryos might due to the short period of exposure time. Zebrafish eggs have high concentration of retinol [39], which indicates that those retinol preexisting in the embryos is enough for supporting the early stage development. When sugjected to the exogenous stress, those retinol can be mobilized and excreted into the plasma to maintain the developmental homeostasis [40].

The transcriptional expression of the retinol binding protein (rbp4) had no significant changes after treated with topramezone, suggesting that plasma retinol had been transmitted to target tissues normally. However, the contents of retinal were decreased in the higher concentration of topramezone exposure. These results suggested that the retinol cellular transport pathway was disrupted and caused little retinol being transformed into retinal.

RA has been reported to play an important role in regulating its production through a negative feedback mechanism by inhibition of raldh2 expression [41]. In the present study, the transcriptional expression of raldh2 was up-regulated, which suggested that lower contents of RA could stimulate the production of RA. The mRNA expression level of cyp26a is independent of endogenous RA contents through raldh2 in zebrafish embryos [42]. However, the transcriptional levels of cyp26a had no obviously changes, which indicated that there was a constant capability for RA degradation in zebrafish during embryonic development.

In zebrafish, raraa, partly functional overlaps with raldh2 and crabp2a, that is existed in the hindbrain, tailbud and eye [43]. Thus, the downregulation of 
raraa mRNA expression levels in the present study demonstrated that the RA concentrations in target tissues were decreased.

RA plays a key role in the visual systems of vertebrates for photoreceptor development [44]. Many genes involved in eye morphogenesis are regulated by RA through its binding and interacting with the RARs and RXRs [45]. RA also plays a vital role in controlling the retina photoreceptors development in animals. Treatment of exogenous RA results in duplication of the retina during optic primordial development in fish [46]. Thus, the reduced RA contents might also had an adverse effect on the development of photoreceptors. In this study, the mRNA expression levels of zfrho, zfuv, zfred, zfblue, and zfgr1, that encode rhodopsin, ultraviolet, red, blue and green opsins, respectively, were significantly increased in the topramezone treated zebrafish larvae. These data indicated that reduced chromophore retinal and the disturbance of $\mathrm{RA}$ signaling in eye photoreceptors in the response to topramezone. Further studies are needed to evaluate the effects of long time exposure to relevantly environmental levels of topramezone on the retinoid homeostasis and eye development in the aquatic animals. 


\section{REFERENCES}

1. Grossmann, K. and T. Ehrhardt, On the mechanism of action and selectivity of the corn herbicide topramezone: a new inhibitor of 4 - hydroxyphenylpyruvate dioxygenase. Pest management science, 2007. 63(5): p. 429-439.

2. Meyer, J.W. and B.E. Branham, Response of four turfgrass species to ethofumesate. Weed technology, 2006. 20(1): p. 123-129.

3. Kraehmer, H., et al., Herbicides as weed control agents: state of the art: II. Recent achievements. Plant physiology, 2014. 166(3): p. 1132-1148.

4. Beckie, H.J. and F.J. Tardif, Herbicide cross resistance in weeds. Crop Protection, 2012. 35: p. 15-28.

5. McELROY, J. and D. Martins, Use of herbicides on turfgrass. Planta daninha, 2013. 31(2): p. 455-467.

6. Chhokar, R.S., R.K. Sharma, and I. Sharma, Weed management strategies in wheat-A review. Journal of Wheat Research, 2012.4(2).

7. Jhala, A.J., et al., Integrated weed management in maize, in Recent Advances in Weed Management. 2014, Springer. p. 177-196.

8. Relyea, R.A., The impact of insecticides and herbicides on the biodiversity and productivity of aquatic communities. Ecological applications, 2005. 15(2): p. 618-627.

9. Schulz, R., Field studies on exposure, effects, and risk mitigation of aquatic nonpoint-source insecticide pollution. Journal of Environmental Quality, 2004. 33(2): p. 419-448. 
10. Wojtaszek, B.F., et al., Effects of Vision ${ }^{\circledR}$ herbicide on mortality, avoidance response, and growth of amphibian larvae in two forest wetlands.

Environmental Toxicology and Chemistry, 2004. 23(4): p. 832-842.

11. Tatum, V.L., Toxicity, transport, and fate of forest herbicides. Wildlife Society Bulletin, 2004. 32(4): p. 1042-1048.

12. Annett, R., H.R. Habibi, and A. Hontela, Impact of glyphosate and glyphosate based herbicides on the freshwater environment. Journal of Applied Toxicology, 2014. 34(5): p. 458-479.

13. Bollman, J.D., et al., Efficacy and tolerance to HPPD-inhibiting herbicides in sweet corn. Weed Technology, 2008. 22(4): p. 666-674.

14. Grossmann, K., et al., On the mode of action of the herbicides cinmethylin and 5 - benzyloxymethyl - 1,2 - isoxazolines: putative inhibitors of plant tyrosine aminotransferase. Pest management science, 2012. 68(3): p. 482-492.

15. Gitsopoulos, T.K., V. Melidis, and G. Evgenidis, Response of maize (Zea mays L.) to post-emergence applications of topramezone. Crop protection, 2010. 29(10): p. 1091-1093.

16. Antonenko, A.M., et al., Mechanism of action of 4-hydroxyphenylpyruvate dioxygenase inhibitor herbicide on homoterm animals and humans. Journal of Pre-Clinical and Clinical Research, 2015. 9(2).

17. Li, Y., et al., Miniaturized liquid-liquid extraction coupled with ultraperformance liquid chromatography/tandem mass spectrometry for determination of topramezone in soil, corn, wheat, and water. Analytical and bioanalytical chemistry, 2011.400(9): p. 3097-3107. 
18. Matthews, G., Pesticides: health, safety and the environment. 2015: John Wiley \& Sons.

19. Dolle, P., et al., Retinoic acid receptors and cellular retinoid binding proteins. I. A systematic study of their differential pattern of transcription during mouse organogenesis. Development, 1990. 110(4): p. 1133-1151.

20. Duester, G., Retinoic acid synthesis and signaling during early organogenesis. Cell, 2008. 134(6): p. 921-931.

21. Mao, R., et al., AIBP Limits Angiogenesis Thorough $\gamma$-Secretase-Mediated Upregulation of Notch Signaling. Circulation Research, 2017: p. CIRCRESAHA. 116.309754 .

22. Sandell, L.L., et al., RDH10 oxidation of Vitamin A is a critical control step in synthesis of retinoic acid during mouse embryogenesis. PloS one, 2012. 7(2): p. e30698.

23. Moise, A.R., J. Von Lintig, and K. Palczewski, Related enzymes solve evolutionarily recurrent problems in the metabolism of carotenoids. Trends in plant science, 2005.10(4): p. 178-186.

24. Cherbas, L., et al., EcR isoforms in Drosophila: testing tissue-specific requirements by targeted blockade and rescue. Development, 2003.130(2): p. $271-284$

25. Carlberg, C. and T.W. Dunlop, An integrated biological approach to nuclear receptor signaling in physiological control and disease. Critical Reviews ${ }^{\mathrm{TM}}$ in Eukaryotic Gene Expression, 2006. 16(1). 
26. Tran, H., et al., Requirement of co-factors for the ligand-mediated activity of the insect ecdysteroid receptor in yeast. Journal of molecular endocrinology, 2001. 27(2): p. 191-209.

27. Zile, M.H., Function of vitamin A in vertebrate embryonic development. The Journal of nutrition, 2001.131(3): p. 705-708.

28. Niederreither, K. and P. Dollé, Retinoic acid in development: towards an integrated view. Nature Reviews Genetics, 2008. 9(7): p. 541-553.

29. Paganelli, A., et al., Glyphosate-based herbicides produce teratogenic effects on vertebrates by impairing retinoic acid signaling. Chemical research in toxicology, 2010. 23(10): p. 1586-1595.

30. Meng, S., et al., Transdifferentiation Requires iNOS ActivationNovelty and Significance. Circulation Research, 2016. 119(9): p. e129-e138.

31. Zhai, G., et al., Sept6 is required for ciliogenesis in Kupffer's vesicle, the pronephros, and the neural tube during early embryonic development. Molecular and cellular biology, 2014. 34(7): p. 1310-1321.

32. Gu, Q., et al., Genetic ablation of solute carrier family 7a3a leads to hepatic steatosis in zebrafish during fasting. Hepatology, 2014. 60(6): p. 1929-1941.

33. Kimmel, C.B., et al., Stages of embryonic development of the zebrafish. Developmental dynamics, 1995. 203(3): p. 253-310.

34. Zhong, L., et al., Investigation of effect of $17 \alpha$-ethinylestradiol on vigilin expression using an isolated recombinant antibody. Aquatic toxicology, 2014. 156: p. 1-9. 
35. Gu, Q., et al., Generation and characterization of a transgenic zebrafish expressing the reverse tetracycline transactivator. Journal of Genetics and Genomics, 2013.40(10): p. 523-531.

36. Yang, X., et al., Nucleoporin 62-like protein activates canonical Wnt signaling through facilitating the nuclear import of $\beta$-catenin in zebrafish. Molecular and cellular biology, 2015. 35(7): p. 1110-1124.

37. Song, G., et al., Effective gene trapping mediated by Sleeping Beauty transposon. PloS one, 2012.7(8): p. e44123.

38. Karpińska, J., et al., HPLC method for simultaneous determination of retinol, $\alpha$ tocopherol and coenzyme $Q 10$ in human plasma. Journal of pharmaceutical and biomedical analysis, 2006. 42(2): p. 232-236.

39. Solomon, K.R., et al., Effects of atrazine on fish, amphibians, and aquatic reptiles: a critical review. Critical reviews in toxicology, 2008. 38(9): p. 721772.

40. Nieman, K.M., et al., Adipose tissue and adipocytes support tumorigenesis and metastasis. Biochimica et Biophysica Acta (BBA)-Molecular and Cell Biology of Lipids, 2013. 1831(10): p. 1533-1541.

41. Greiling, T.M. and J.I. Clark, 1 New Insights into the Mechanism of Lens Development Using Zebra Fish. International review of cell and molecular biology, 2012. 296: p. 1.

42. Dobbs-McAuliffe, B., Q. Zhao, and E. Linney, Feedback mechanisms regulate retinoic acid production and degradation in the zebrafish embryo. Mechanisms of development, 2004. 121(4): p. 339-350. 
43. Hale, L.A., et al., Characterization of the retinoic acid receptor genes raraa, rarab and rarg during zebrafish development. Gene expression patterns, 2006. 6(5): p. 546-555.

44. Cvekl, A. and W.-L. Wang, Retinoic acid signaling in mammalian eye development. Experimental eye research, 2009. 89(3): p. 280-291.

45. Novák, J., M. Beníšek, and K. Hilscherová, Disruption of retinoid transport, metabolism and signaling by environmental pollutants. Environment international, 2008. 34(6): p. 898-913.

46. Hyatt, G.A., et al., Retinoic acid-induced duplication of the zebrafish retina. Proceedings of the National Academy of Sciences, 1992. 89(17): p. 82938297. 
Table 1 Retinoid profiles (ng/mg protein) in zebrafish embryos treated with topramezone

\begin{tabular}{ccccc}
\hline & $0 \mu \mathrm{g} / \mathrm{L}$ & $1 \mu \mathrm{g} / \mathrm{L}$ & $10 \mu \mathrm{g} / \mathrm{L}$ & $100 \mu \mathrm{g} / \mathrm{L}$ \\
\hline Retinol & $140.3 \pm 11.2$ & $135.4 \pm 12.1$ & $142.2 \pm 5.8$ & $132.2 \pm 17.9$ \\
Retinal & $90.1 \pm 3.1$ & $112.1 \pm 3.4$ & $70.8 \pm 12.4$ & $40.2 \pm 10.5$ \\
Retinoic acid & $16.2 \pm 2.1$ & $12.6 \pm 2.1$ & $6.8 \pm 1.2^{*}$ & N.D. ${ }^{* *}$ \\
\hline
\end{tabular}

N.D., not detected.

$\square$ Significant differences compared to the control group (One-way ANOVA,

followed by Tukey's test: $p<0.05)$.

Significant differences compared to the control group (One-way ANOVA,

followed by Tukey's test: $p<0.01$ ). 
Figure 1 Transcriptional expression levels of crbp1a, rdh1, raldh2, crabp1a, crabp2a and raraa in zebrafish exposed to topramezone.

$0 \mu \mathrm{g} / \mathrm{L}-1 \mu \mathrm{g} / \mathrm{L} \quad 10 \mu \mathrm{g} / \mathrm{L}$

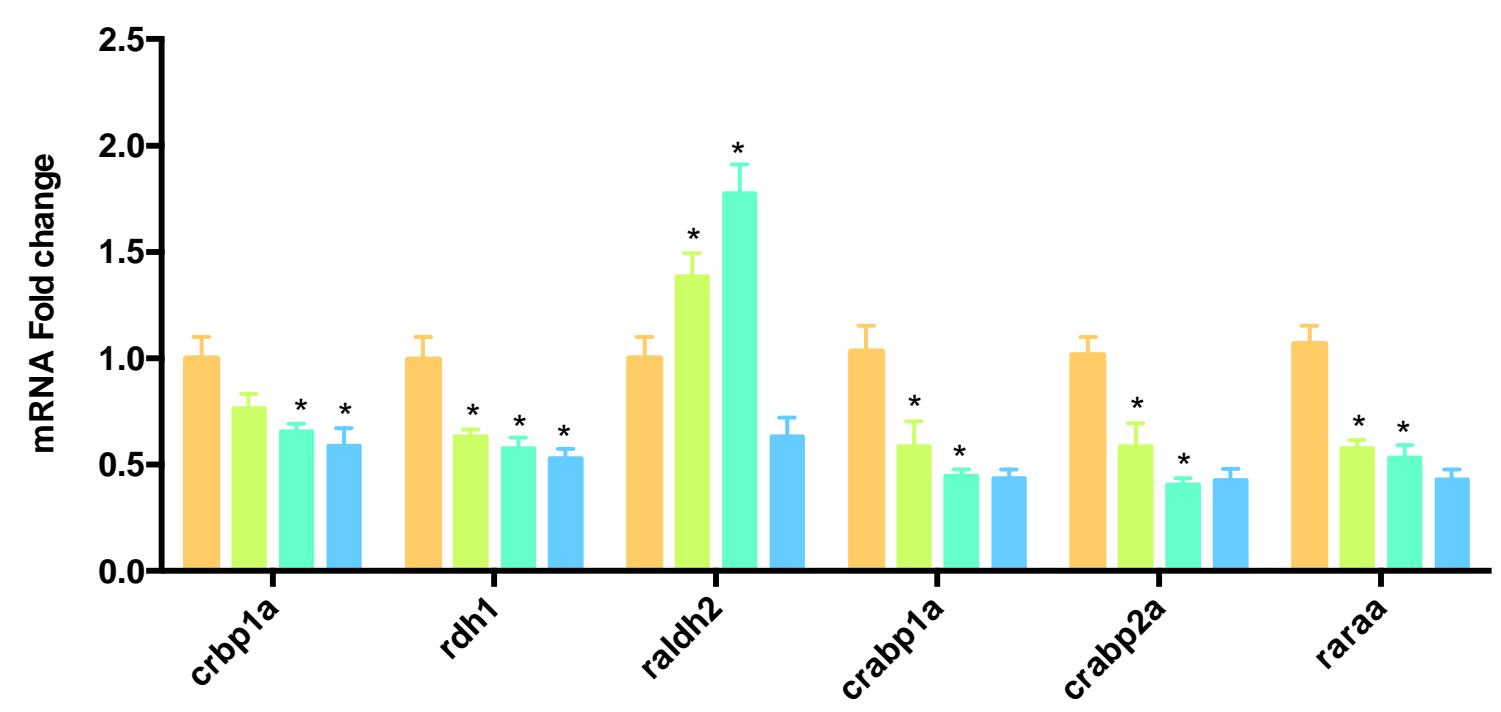


Figure 2 The mRNA expression levels of zfrho, zfuv, zfred, zfblue and zfgr1 in zebrafish exposed to topramezone.

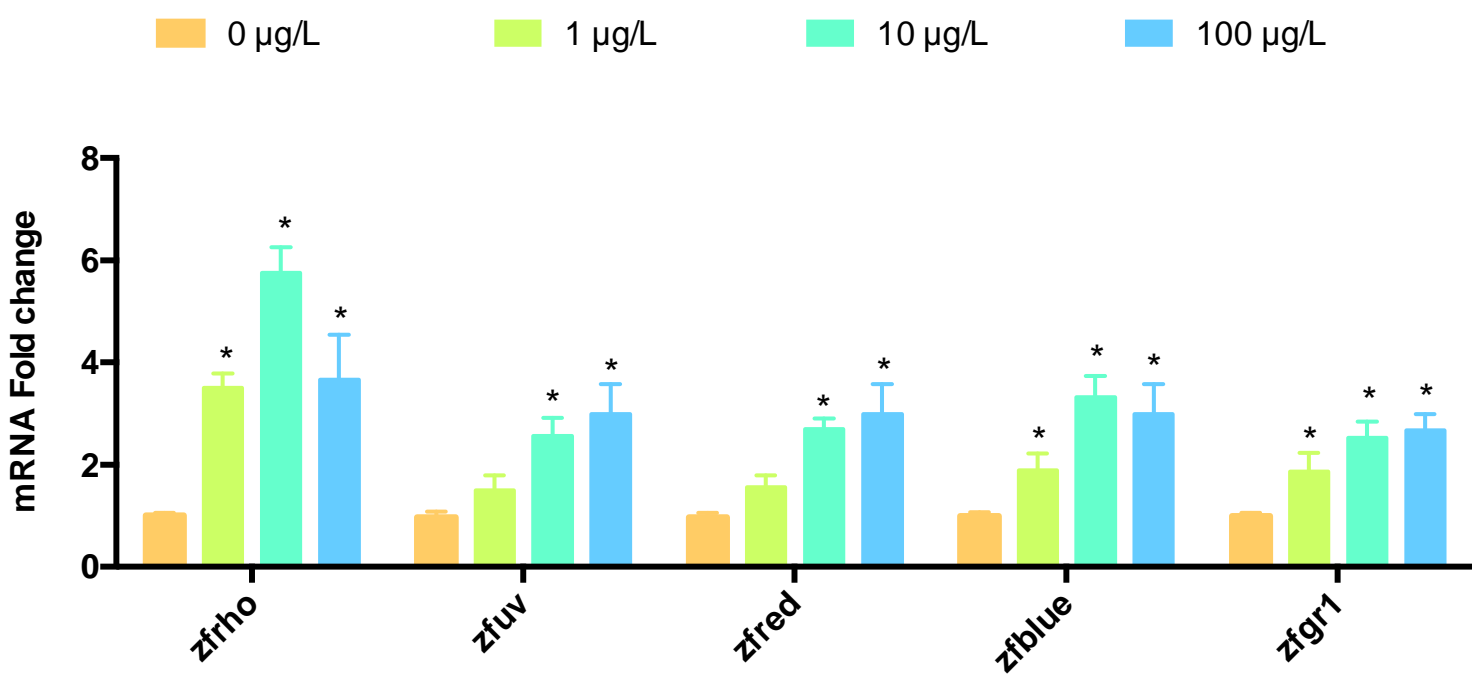

